Original Research

\title{
Melting/Solidification Processes of PEG 1500 in Vertical and Horizontal Annular Enclosure
}

\author{
F. A. Hamad *, E. Egelle, Abbas Mohammed, S. Gooneratne, P. Russell
}

School of Science, Engineering and Design, Teesside University Middlesbrough, United Kingdom; EMails: F.hamad@tees.ac.uk; enenike e@yahoo.co.uk; P4195752@tees.ac.uk;

S.Gooneratne@tees.ac.uk; p.russell@tees.ac.uk

* Correspondence: F. A. Hamad; E-Mail: F.hamad@tees.ac.uk

Academic Editor: Joaquin Alonso-Montesinos

Special Issue: Photovoltaic Solar Systems and Solar Thermal Plants

Journal of Energy and Power Technology

2021, volume 3, issue 1

doi:10.21926/jept.2101009
Received: December 01, 2020

Accepted: January 21, 2021

Published: January 31, 2021

\begin{abstract}
In this paper, the primary aim is to look at the fundamental melting/solidification processes of polyethylene glycol 1500 (PEG 1500) for energy storage - insulation to prolong the cooling time of pipelines in unexpected shut-down conditions, prevent/minimize the wax deposition, and hydrate formation. Polyethylene glycol 1500 was selected because its melting temperature is $>317 \mathrm{~K}$ making it a suitable candidate as lagging material to prevent wax deposition and hydrate formation in subsea oil pipelines. Experimental apparatus was designed with the Perspex to give an insight into the melting process. Vertical and horizontal annular geometries were used to consider the real-life cases. The vertical annular enclosure length is $950 \mathrm{~mm}$ and $34 \mathrm{~mm}$ width (Height/Width=27.94). The horizontal annular enclosure length is $300 \mathrm{~mm}$ and $15.9 \mathrm{~mm}$ width (Height/Width=18.87). The thermocouples and camera are used to collect the data for three cases of inner wall temperature of $333 \mathrm{~K}, 343 \mathrm{~K}$ and 353 $\mathrm{K}$ where is the heat added to the phase change material (PCM) for both cases. The main conclusions are: i) the horizontal annular case melt faster than the vertical case, in particular, at higher heating surface temperature of $353 \mathrm{~K}$, ii)The temperature of the inner region was remained hot for long time which provide a good evidence that support the concept of using
\end{abstract}

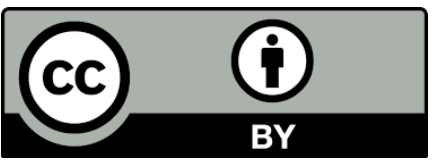

(C) 2021 by the author. This is an open access article distributed under the conditions of the Creative Commons by Attribution License, which permits unrestricted use, distribution, and reproduction in any medium or format, provided the original work is correctly cited. 
the PCM as heat storage-insulation material; iii) the melting percentage for horizontal case is $100 \%$ higher from the melting percentage of vertical case at $333 \mathrm{~K}$ which reduced to about $20 \%$ for $343 \mathrm{~K}$, iv) increasing the heating surface temperature substantially reduces the total melting time for both orientations.

\section{Keywords}

Annular geometry; melting/solidification; latent heat energy; storage - insulation application; polyethylene glycol 1500 (PEG 1500)

\section{Introduction}

The applications of the annular geometry are related to the shell and tube heat exchangers and thermal storage-reuse systems where the PCM exists in the annular space. Melting and solidification of the PCM occurs when there is heat exchange between the PCM and the hot fluid/ambient. This annular geometry could be horizontal, inclined or vertical based on the type of the application.

The new application of the present work is to prevent the wax deposits on the pipe wall and the hydrate formation at temperature less than $317 \mathrm{~K}$ The gas hydrates are an ice-like formation that can be formed under high pressure and low temperature conditions, when water become in contact with methane, ethane, hydrogen sulphide, carbon dioxide, etc. The gas molecules will be caged in the water molecules. The gas hydrates form solid ice plugs which will cause restricted flows and a full blockage. The wax deposition is another problem cause blockage of oil pipeline. As wax deposition and hydrate formation are mainly a result of cold temperatures, a prevention method in the form of thermal storage would make a perfect fitting towards attempting to solve the problem The PCM (Polyethylene glycol 1500 for synthesis. CAS 25322-68-3, 807489 SigmaAldrich, MERCK) selected for this study was polyethylene glycol 1500 (melting temperature= 337 $341 \mathrm{~K}$ ) due to the ease of sourcing and low-cost benefits.

The main objectives of most of the publications in literature were to develop the knowledge in this area to improve the design and performance of the thermal storage systems by improving the rate of heat transfer. A number of ideas were on enhancing the heat transfer to accelerate the charging and discharging of energy such as fins [1-3] or changing the dimension of the system such as outer radius/inner radius ratio and length/diameter ratio [4, 5]. A summary of some recent publications on annular enclosure are given hereafter.

Ismail and Mello [5] developed a 2-dimensional model to study the effect of the outer shell to inner tube radius ratio (Ro/Ri) on the thermal performance of a PCM in a vertical cylinder. The results indicated that the solidification mass fraction decreased and the time necessary for the complete fusion increased by increasing Ro/Ri.

Longeon et al. [6] investigated experimentally and numerically, the heat exchange involved in a vertical annular latent storage unit filled with paraffin RT35. A testing loop with visualisation is built to analyse the influence of the heat transfer fluid (HTF) injection side on the system. The experimental test section is modelled with CFD simulations to explain the charge and discharge 
results. The combined study proves that an injection side coupled with free convection heat transfer mechanism influences the evolution of the PCM melting front.

Seddegh et al. [4] studied the effect of the geometrical and operational parameters on vertical cylindrical shell-and-tube latent heat thermal energy storage (LHTES) systems. Four different ratios of the shell-to-tube radius are considered with the PCM on the shell side and the heat transfer fluid (HTF) flowing through the tube. The results show that a shell to tube radius ratio of 5.4 gave better system performance in terms of the charging time and stored energy. The HTF temperature shows a reduction $68 \%$ in the charging time when the HTF temperature increases from 343 to $353 \mathrm{~K}$.

Kalapala and Devanuri [7] presented a numerical investigation on melting characteristics of a PCM placed in the annulus of a vertical shell and tube thermal storage unit of L/D ratio of 1-10. They found that increasing length/diameter (L/D) ratio increased the total melting time. By increasing L/D ratio from 1 to 4, total melting time increased by 1.75 times. They also found that mentioned that the shell to tube diameter ratio and L/D ratio are the design parameters, which need to be optimized.

Balikowski and Mollendort [8] investigated the melting process of two PCMs (Climsel 28 and Thermasorb 83) in a horizontal annulus unit. Bare- and spine fin-pipe latent heat thermal energy storage units were tested. Their results shown that the rate of charging (melting) and discharging (solidification) was improved with using fins.

Agyenim et al. [9] experimentally studied the erythritol melting/solidification processes in horizontal annulus heat thermal energy storage. They used three storage configurations including bare tube, circular finned tube and longitudinal finned tube. They observed that the longitudinal fins contributed in the best thermal performance of the LHTES unit amongst the other studied cases.

Azad et al. [10] investigated the melting of PCM in a cylindrical enclosure experimentally and numerically. The n-octadecane has been melted at HTF temperatures of 313, 323 and $333 \mathrm{~K}$. For 6 hours of heating, a linear increase in stored energy is observed at low wall temperature. At high wall temperatures, melting of the PCM slows down after a certain time. Once all melted, most of the energy still goes to the upper portion in the form of sensible heat to the liquid PCM, which slows down the melting of the PCM below the heating tube which is driven by conduction.

Jesumathy et al. [11] investigated the melting/solidification of Paraffin wax in horizontal double-pipe LHTES unit. They showed that heat transfer rate increased by $25 \%$ and $11 \%$ when the inlet temperature of HTF increased and decreased by $275 \mathrm{~K}$, respectively.

Pahamli et al. [12] also investigated the effect of inner pipe eccentricity on melting process of RT50 in the annular space of a horizontal double-pipe. They observed that the downward movement of the inner pipe contributed in the significant enhancement of the PCM melting process by shortening the total melting time by $64 \%$.

Tabassum [13] investigate the melting characteristics of impure PCM embedded between two concentric circular horizontal cylinders. The inner cylindrical tube was heated to a constant temperature by a heat transfer fluid while the outer tube was insulated. The results show that the melting rate increases rapidly up to the melting time of about $41.18 \mathrm{~min}$. Then, the melting rate increases but at much slower rate. The storage of thermal energy increases with the increase of the inner wall temperature and initial temperature of the solid PCM. The energy charged is greatly 
influenced by the change of the inner tube wall temperature compared to the change of the initial solid PCM temperature

Gortychet al. [14] examine the process of heat accumulation and heat release for PCM in an annular space analytically and experimentally. The results showed that the thickness of the solidification layer depending on time and the distribution of the local heat transfer coefficient on the surface of the solidification front.

Mustafa et al. [15] compare the melting/solidification process between the PCM in the annulus (case A) and the inner tube (case B) numerically. The results showed that the melting time was significantly different in the two cases. it was shorter in case B than case A by almost $50 \%$. The results revealed that the solidification process in case $A$ was more rapid than case $B$ with the total solidification time of case $A$ being lower by $43.4 \%$.

Saeid et al. [16] investigated the thermal behaviour in a vertical and horizontal shell-and-tube energy storage system using PCMs. The results indicate that the horizontal orientation has superior thermal performance during the charging and during part load energy charging. The results also show that increasing the hot HTF inlet temperature substantially reduces the total charging time for both orientations.

Al Siyabi I et al. [17] investigated the effect of inclination angle on melting of PCM in cylindrical thermal storage system. They found that the direction of buoyant force resulting from the melted liquid PCM has a major role in both melting rate and melting direction within the PCM storage.

From the above-mentioned works, the major influencing operating parameter is heating temperature, the inner and outer radius of the annular geometry and the length/width ratio of the annulus. Although, there are some experimental and numerical studies on annular geometry for thermal storage-reuse applications, but there is a need for more experimental data to fully understand the behaviour of melting and solidification process for thermal storage-insulation applications. In this study, experimental rig was built to study experimentally the melting/ solidification process of PEG 1500 in vertical annular enclosure of $950 \mathrm{~mm}$ length and $34 \mathrm{~mm}$ width and horizontal annular enclosure of $300 \mathrm{~mm}$ length and $15.9 \mathrm{~mm}$. The objectives of this paper are: i) To generate and report experimental data for the melting and solidification of the PCM from the inside to the outer side of the PCM annulus; ii) Use the recorded temperature to construct the melting front evolution during the melting process of vertical annulus; iii) Use the recorded temperature to construct the solidification contour. iv) Compare the melting percentage of the PCM between the vertical and horizontal annular geometry.

\section{Experimental Set-up and Procedure}

\subsection{Experimental Set-Up and PCM Compartment}

The experimental setup shown in Figure 1a for vertical and horizontal annular cases. The main components of the experimental set up comprise of, the heating water bath, thermocouples to measure temperature, temperature monitoring system (Pico data logger) and image recording system (digital camera). The thermocouples (TC) were placed in the PCM domain at different locations as shown in Figure $1 \mathrm{~b}$ for the vertical annular case and in Figure $1 \mathrm{c}$ for horizontal annular case. This apparatus has been designed with the Perspex to give an insight into the melting process. 
a

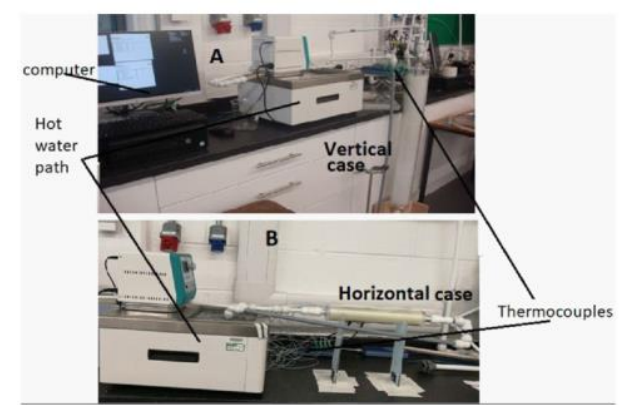

C

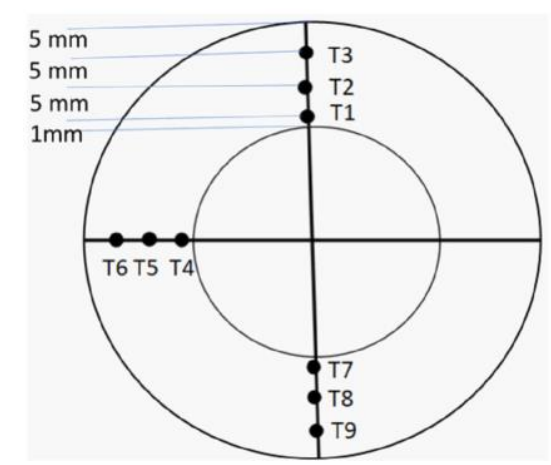

b

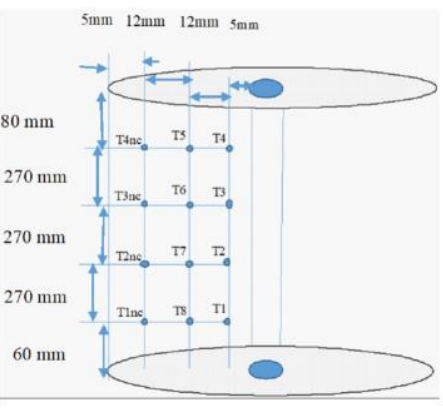

Figure 1 a. Photograph of the experimental set-up; b. Schematic diagram of the experimental set up showing the location of thermocouples in the vertical annular space dimensions; c. Schematic diagram of the experimental set up showing the location of thermocouples in the horizontal annular space dimensions.

The vertical annulus enclosure is formed from an outside cylinder made from a Perspex pipe $950 \mathrm{~mm}$ total length ( $\mathrm{H}$ : height in rectangular enclose), outer diameter of $114 \mathrm{~mm}$ and inner diameter of $102 \mathrm{~mm}$. The inner aluminium pipe cylinder has $34 \mathrm{~mm}$ outer diameter, $28 \mathrm{~mm}$ inner diameter and 1,140 $\mathrm{mm}$ in length. The width of the annulus ( $\mathrm{W}=$ inner diameter of Perspex pipe outer diameter of aluminium pipe) is $34 \mathrm{~mm}$ and $950 \mathrm{~mm}$ length $(\mathrm{H} / \mathrm{W}=27.94)$. For larger volumes of PCM used in these experiments, the expansion upon melting becomes significant. This dictates that some free space $(50 \mathrm{~mm})$ filled with air is left above the PCM to allow room for the material to expand. The thermocouple attached in the space between the aluminium pipe and Perspex pipe by using ring shape thermocouples holder to stop them from being moved during the melting process.

The horizontal annulus enclosure was constructed from $3 \mathrm{~mm}$ thick Perspex material with dimensions of $300 \mathrm{~mm}$ long $\times 54 \mathrm{~mm}$ inner diameter, and $300 \mathrm{~mm}$ long $\times 22 \mathrm{~mm}$ outer diameter with $3 \mathrm{~mm}$ thick aluminium material. These dimensions produce annular space of $300 \mathrm{~m}$ length (L) and $16 \mathrm{~mm}$ width (W) $(\mathrm{L} / \mathrm{W}=18.75)$. Free space of $15 \mathrm{~mm}$ from the annular length was left filled with air to allow space for PCM expansion.

The molten PCM was poured into the annular section of both enclosures whilst ensuring that no air bubbles were left in the PCM. The inner cylindrical aluminium pipe is connected to the hot water inlet from the heating water bath. The heating water bath is maintained at a constant temperature by the pump in a flowing circulation heater. The hot water flows through the aluminium tube. The desired temperature is maintained by heating the fluid with a controlled temperature heating water bath. The water bath continued to provide isothermal boundary 
condition of $353 \mathrm{~K}$ throughout the experimental progression. Tests were also performed at constant isothermal boundary conditions of 343 and $333 \mathrm{~K}$ respectively. All parts of the test sections were tightly joined to avoid any leakage. The maximum heat charging experiment duration is 375 mints.

The procedure for the experiment is therefore summarized below:

1. Turn on the power supply of the thermocouples control unit.

2. Turn on the heating water bath by adjusting the thermal control unit to certain desired heating temperature.

3. Open the valve and let the flow commence at the pump speed with an acceptable water volume flow rate

4. With the water circulation fully established at the required volume flow rate, record the temperature readings throughout the period of all the experiment.

\subsection{PCM Filling Procedure}

The main challenge while loading the PCM inside the enclosure is to maintain uniform PCM concentration in the entire annular cylindrical domain. In order not to have a segregation of the waxy particle inside the annular space, the waxy particles were first heated. The heating of the PCM to melting point was achieved using a heating plate maintained at a temperature above the melting point of the PCM ( $333 \mathrm{~K})$. Once the melting is achieved, the content is immediately turned into the annular space to minimize the air bubble in the solidified PCM.

\subsection{Thermocouple for Temperature Data Acquisition}

The PCM temperatures inside the vertical annular cylindrical enclosure were measured by Type-K thermocouples. Twelve thermocouples were mounted at different locations in the same plane of the vertical annular section of the cylinder as shown in Figure $1 \mathrm{~b}$ to monitor the temperature during the phase change process. The temperature distributions is in angular direction was assumed homogenous as it was shown by Longeon et al [6]. For the horizontal annular case, the thermocouples attached in three planes to record the temperature variation between the top and the bottom of the horizontal annular space as the temperature distribution is not symmetrical as in the vertical case. Nine thermocouples are used and attached on ring shape thermocouples holder at three planes as shown in Figure 1c. On first thermocouples holder, T1 was placed near the Perspex pipe at the top of annulus, T2 attached to the middle point of the holder in horizontal plane. T3 attached near to the lower wall of the aluminium pipe. On the second thermocouples holder, T4 attached to the middle point at the top of the annulus, T5 attached at the top point on horizontal plane, T6 attached to near the lower wall of aluminium pipe. On the third thermocouple holder, T7 attached to the point near the top wall of the aluminium pipe, T8 attached to the middle point on horizontal plane, T9 attached near the lower Perspex wall. This thermocouple arrangement was used to record the temperatures in the vertical plane to show the temperature distribution during the melting process.

The data acquisition system for temperature reading was two 8 Channel Pico log data recorders connected to the computer system. A digital camera was used to capture the images of the PCM melting profile in the cylindrical Perspex pipe during the experiment at specified time intervals. 
The experimental results are influenced by the inaccuracy in measurement of individual instruments. In present work, the uncertainty can be generated from temperature measurements using the thermocouple, the contours of melt front and the fraction of melted PCM which discussed in details by Hamad et al (2017) [18].

\section{Results and Discussion}

\subsection{Melting Evolution in the Vertical Annular Enclosure}

Different temperatures were initiated to establish the evolution of melting process of the PCM in the vertical annular enclosure. The lowest aluminium wall temperature used was the $333 \mathrm{~K}$. After the water flowing over a time of approximately 6 hours. The temperatures from thermocouples and the photos are recorded simultaneously to use both for analysis of melting evolution.

From the temperature records, as the melting front cannot be captured by the camera, before the melting front reach the Perspex pipe wall, the following procedure were used to construct the evolution of melting front using the temperature recoded by thermocouples:

1. The time for each thermocouple reaching the melting temperature $(318 \mathrm{k})$ is recoded.

2. The velocity for melting front is calculated from the distance between the first column of the thermocouples and the aluminium pipe and the time for melting of this distance as recorded in the first step. The same procedure is used for the second and third columns.

3. Then, the velocity and time are used to calculate the distance of the melting front from the aluminium pipe wall.

4. The average diameter of the melting fronts is used to calculate the melted volume. Then the melting percentage calculated by dividing the melted volume by the total annular volume.

The temperature evolution for melting at 333,343 and $353 \mathrm{~K}$ are given in Figures $2 \mathrm{a}, 2 \mathrm{~b}$ and $2 \mathrm{c}$. The images obtained for the cases when the melting front reach the Perspex wall were used to complete the explanation of melting process.

\subsubsection{Melting Evolution for the Case of $333 \mathrm{~K}$}

From the calculation of velocity using the temperature data from Figure $2 \mathrm{a} 1$ and $2 \mathrm{a} 2$, the melting evolution of the PCM at $333 \mathrm{~K}$ is given in Figure 3a. It can be observed that melting started and became steady all through the entire time. This lower temperature was unable to initiate significant melting of the PCM due to the melting temperature not fully reached by the low HTF temperature. The low temperature difference available was not able to create a buoyancy force and natural circulation to enhance heat transfer. The heat transfer by conduction can be considered as the dominated mode of heat transfer, which led to lower rate of heat transfer from the aluminium wall. There is a possibility of the steady state, which was reached, as the heat added to melted zone is approximately equal to overall heat losses from it. 

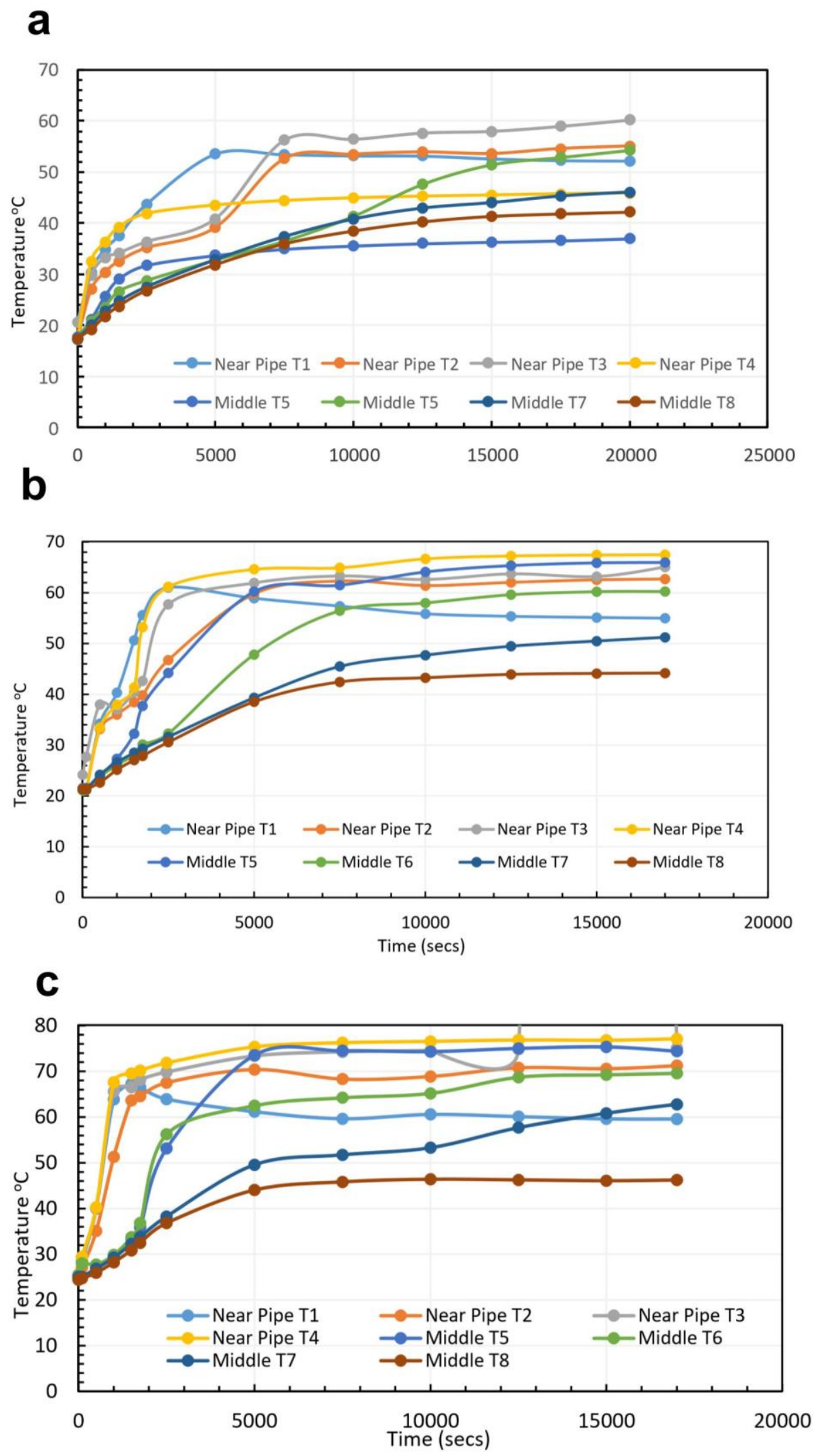

Figure 2 a. The temperature evolution for melting of $60^{\circ} \mathrm{C}$ (vertical case); b. The temperature evolution for melting of $70^{\circ} \mathrm{C}$ (vertical case); c. The temperature evolution for melting of $80^{\circ} \mathrm{C}$ (vertical case). 
a

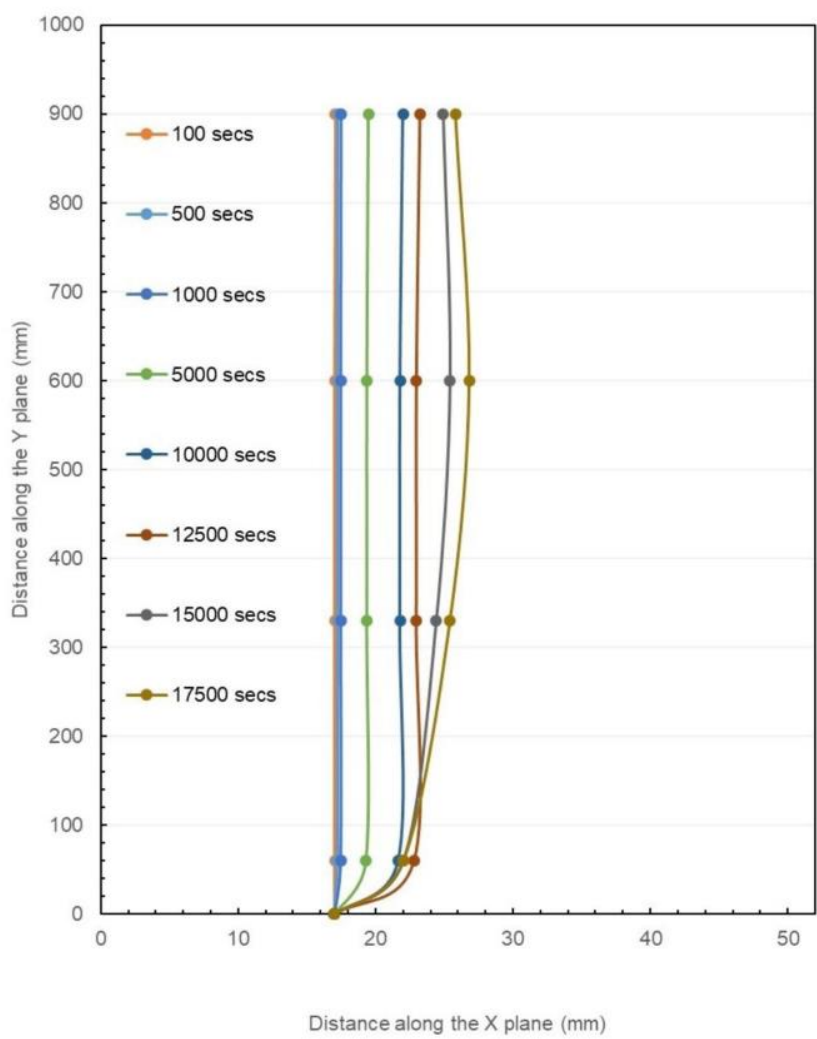

b

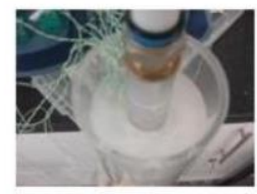

(a) $\mathrm{t}=100 \operatorname{secs}$

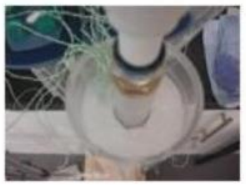

(d) $\mathrm{t}=2500$ secs

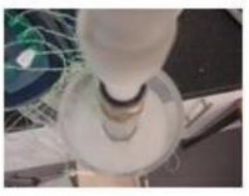

(g) $\mathrm{t}=10000$ secs

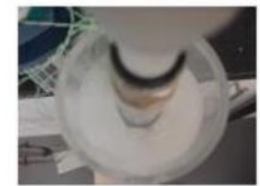

(j) $\mathrm{t}=17500$ secs

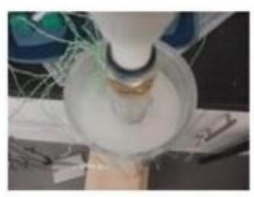

(b) $\mathrm{t}=500$ secs

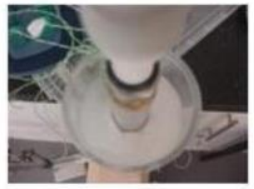

(e) $\mathrm{t}=5000$ secs

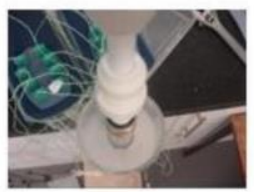

(h) $\mathrm{t}=12500 \mathrm{secs}$

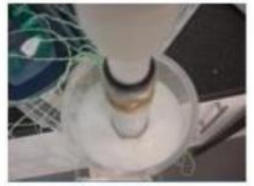

(k) $\mathrm{t}=20000$ secs

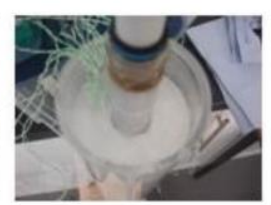

(c) $\mathrm{t}=1000 \mathrm{secs}$

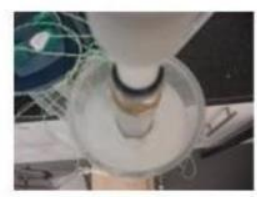

(f) $\mathrm{t}=7500$ secs

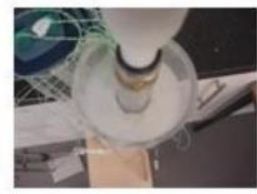

(1) $\mathrm{t}=15000$ secs

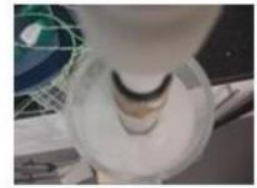

(1) $\mathrm{t}=22500 \mathrm{secs}$

Figure 3 a. The melting front profile of the PCM at the temperature of $60^{\circ} \mathrm{C}$ (vertical case); b. Photographs showing the melting progress for vertical case (heating temperatures $=60^{\circ} \mathrm{C}$ ).

The photos for this case are given in Figure $3 \mathrm{~b}$. It was recorded from the top of the annulus as the melting has progressed more than $10 \mathrm{~mm}$ from the aluminium pipe wall.

\subsubsection{Melting Evolution for the Case of $343 \mathrm{~K}$}

From the calculation of velocity using the temperatures data Figure $2 b 1$ and $2 b 2$, the melting evolution of the PCM at $343 \mathrm{~K}$ is given in Figure 4a. As the temperature higher than case a, the melting front moves faster as can be seen from the larger gaps between the graph reaching the Perspex pipe after around $10000 \mathrm{sec}$ from the start of heating. It can be seen from the images after the $10000 \mathrm{sec}$ that the melting start progressing downward reaching a distance of $150 \mathrm{~mm}$ from the upper level of PCM. This indicates that the higher temperature creates more circulation and increase the heat transfer by convection. The steady state is not reached in this case, as heat input to melted zone is more than the heat losses, which maintain the movement of melting front with the time. 
a

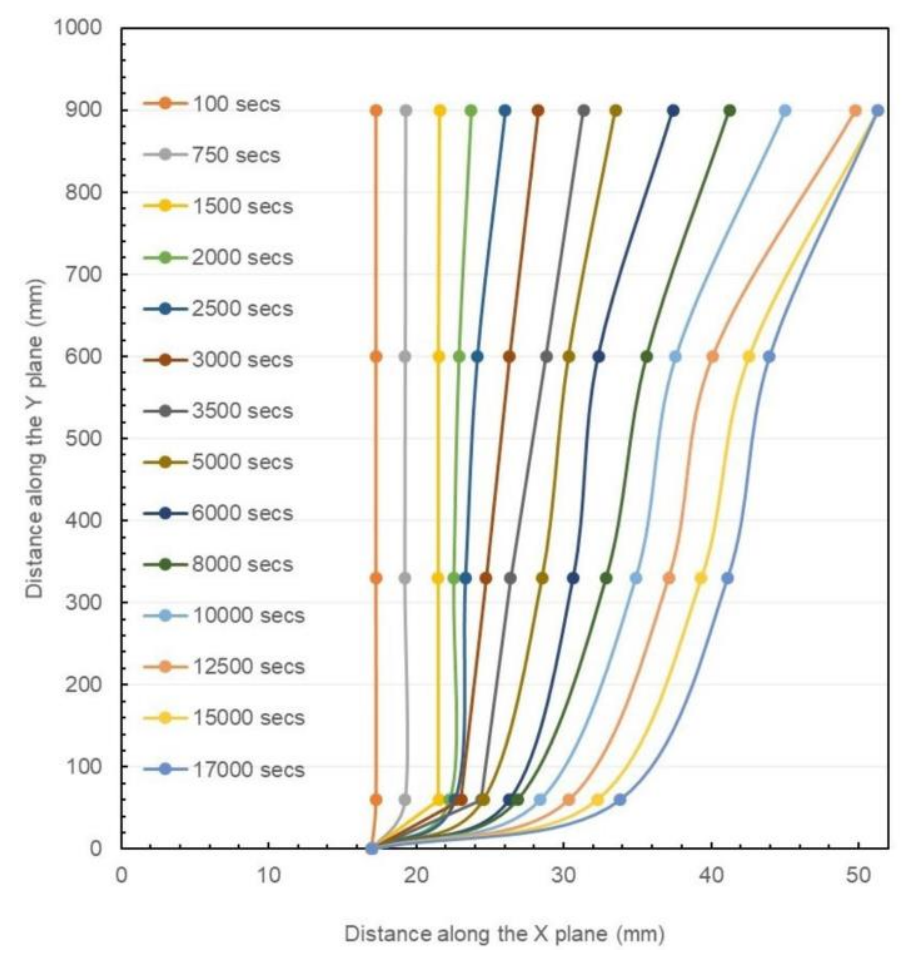

b

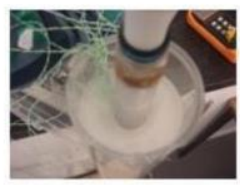

(a) $\mathrm{t}=100$ secs

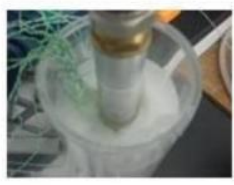

(d) $\mathrm{t}=2500$ secs

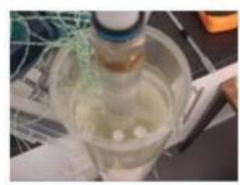

(g) $\mathrm{t}=10000$ secs

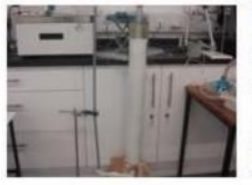

(j) $\mathrm{t}=12500$ secs

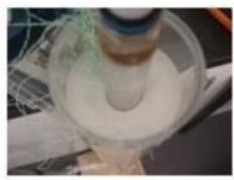

(b) $\mathrm{t}=500$ secs
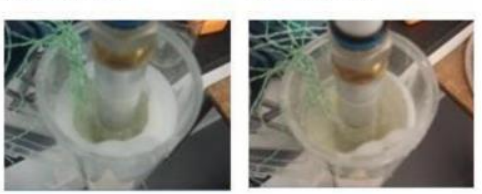

(e) $\mathrm{t}=5000$ secs

(f) $\mathrm{t}=7500$ secs

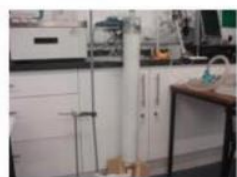

(h) $\mathrm{t}=10000$ secs

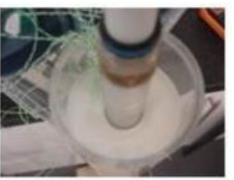

(c) $\mathrm{t}=1000$ secs

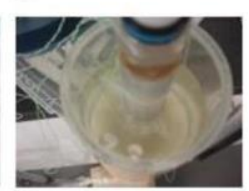

(1) $\mathrm{t}=12500$ secs

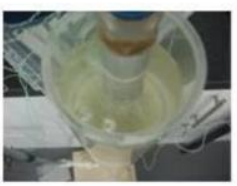

(k) $\mathrm{t}=15000$ secs

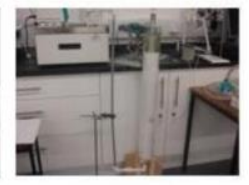

(1) $\mathrm{t}=17500$ secs

Figure 4 a. The melting profile front of the PCM at the temperature of $70^{\circ} \mathrm{C}$ (vertical case); b. Photographs showing the melting progress for vertical case (heating temperatures $=70^{\circ} \mathrm{C}$ ).

\subsubsection{Melting Evolution for the Case of $353 \mathrm{~K}$}

From the calculation of velocity using the temperatures data Figure $2 c 1$ and $2 c 2$, the melting evolution of the PCM at $353 \mathrm{~K}$ is given in Figure $5 \mathrm{a}$. As the temperature higher becomes higher than the cases $a$ and $b$, the melting front moves even faster and reached the Perspex pipe after around $7500 \mathrm{sec}$ from the start of heating. It can be seen from the images after the 7500 secs that the melting start progressing downward reaching a distance of $380 \mathrm{~mm}$ from the upper level of PCM at $15000 \mathrm{sec}$ and $520 \mathrm{~mm}$ at $20000 \mathrm{sec}$. This indicates that the heat transfer by convection becomes very strong compared to conduction which controlled the melting process in case a. The heat transfer is transient as the heat input to the melted zone is much more compared heat losses as the melting front moving much faster than other two cases. Figure 6 shows the variation of melting percentage with time. The melting percentage calculated by dividing the melted volume by the volume of the annular space. 
a

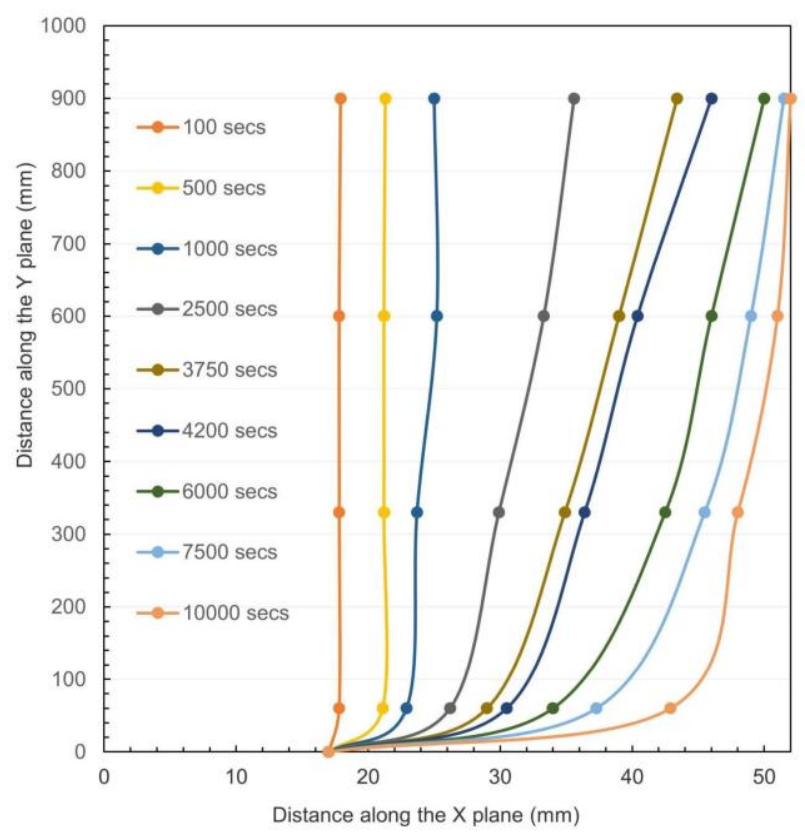

b

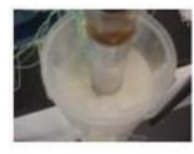

(a) $\mathrm{t}=100 \mathrm{secs}$

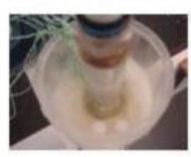

(d) $\mathrm{t}=2500$ secs

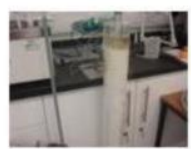

(g) $\mathrm{t}=7500$ secs

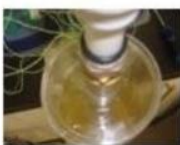

(j) $t=12500$ secs

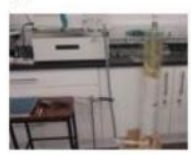

(m) $\mathrm{t}=15000$ secs

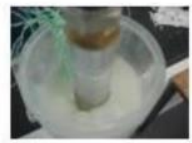

(b) $\mathrm{t}=500 \mathrm{secs}$

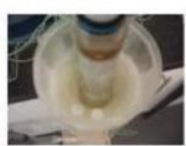

(e) $\mathrm{t}=5000 \mathrm{secs}$

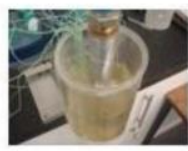

(h) $\mathrm{t}=10000$ secs

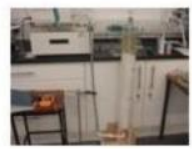

$(k) t=12500$ secs

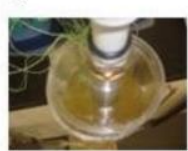

(n) $t=17500$ secs

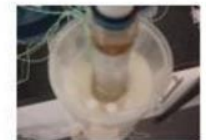

(c) $\mathrm{t}=1000 \mathrm{secs}$

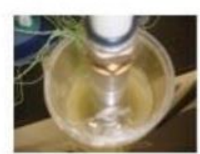

(f) $\mathrm{t}=7500$ secs

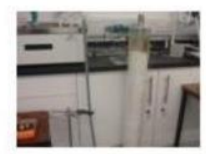

(1) $\mathrm{t}=10000$ secs

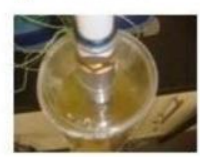

(1) $\mathrm{t}=15000$ secs

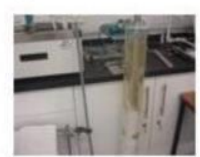

(o) $\mathrm{t}=17500 \mathrm{secs}$

Figure 5 a. The melting profile front of the PCM at the temperature of $80^{\circ} \mathrm{C}$ (vertical case); b. Photographs showing the melting progress for vertical case (heating temperatures $=80^{\circ} \mathrm{C}$ ).

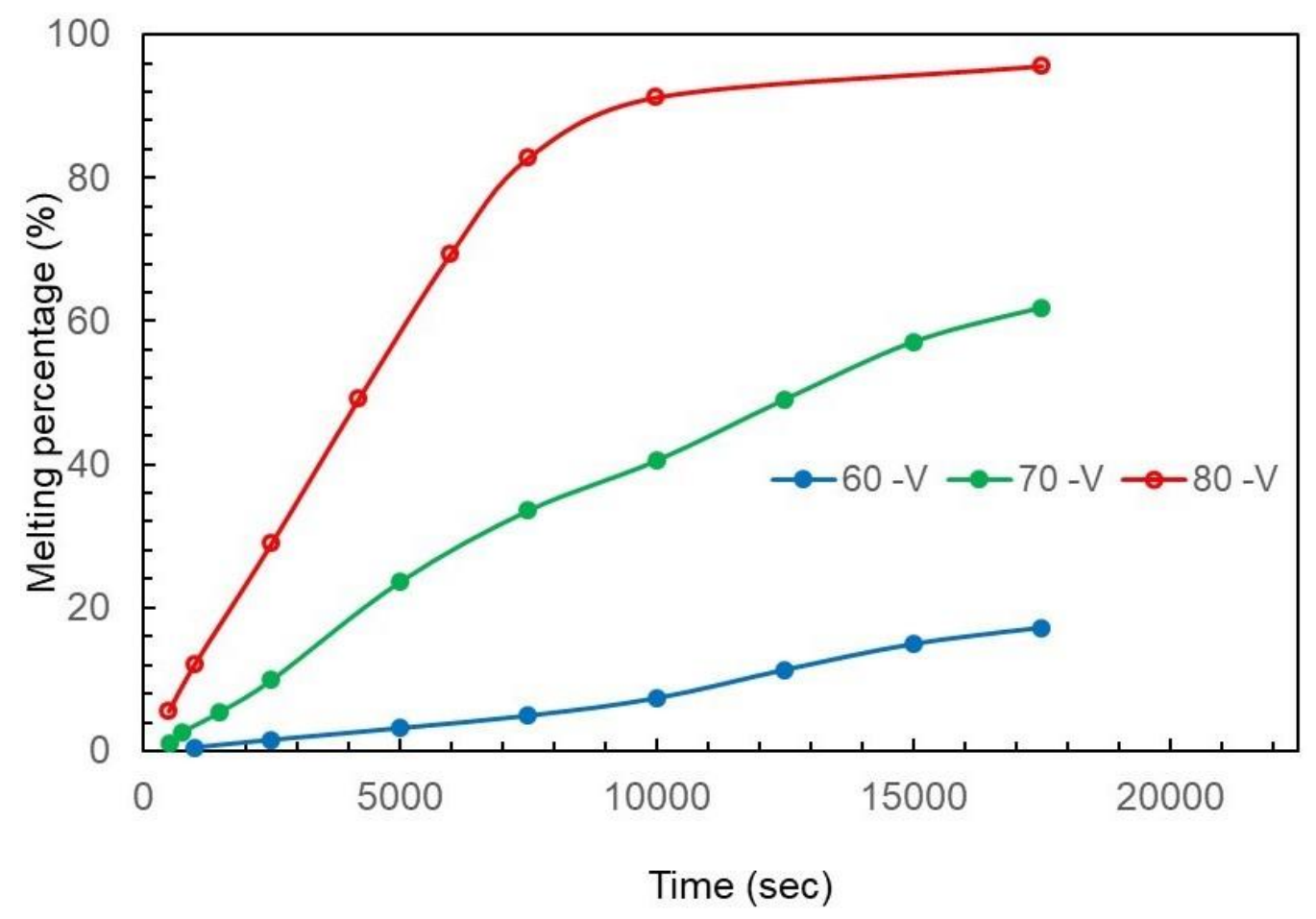

Figure 6 Comparison of melting percentage with time for $60 \mathrm{oC}, 70 \mathrm{oC}$ and $80 \mathrm{oC}$ heating wall (vertical case). 


\subsection{Melting Evolution in the Horizontal Annular Enclosure}

A camera was used to record the melt profile as the melt front progress with the time. Figure $7 \mathrm{a}, 7 \mathrm{~b}$ and $7 \mathrm{c}$ present a sequence of photos of the melting process of PEG 1500 at 333, 343, and $353 \mathrm{~K}$ respectively. Figure 8 shows a comparison of the calculated melting percentage for the three case.

a

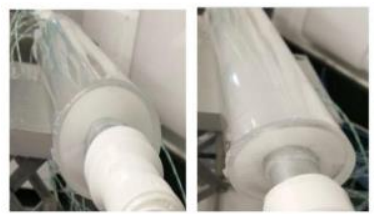

(a) $\mathrm{t}=100 \mathrm{sec}$

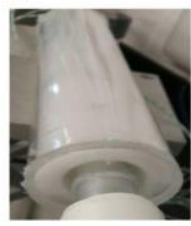

(e) $\mathrm{t}=5500 \mathrm{sec}$

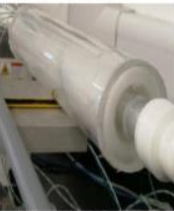

(i) $\mathrm{t}=15500 \mathrm{sec}$

c

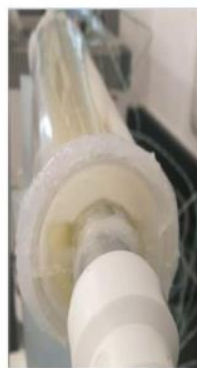

(a) $\mathrm{t}=500 \mathrm{sec}$

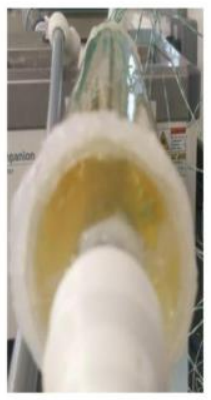

(a) $\mathrm{t}=5500 \mathrm{sec}$ (b) $t=500$ sec

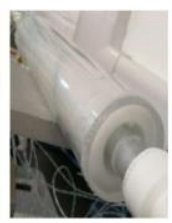

(f) $\mathrm{t}=7500 \mathrm{sec}$

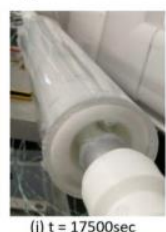

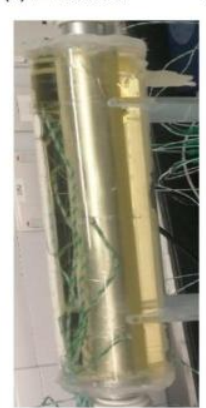

(a) $\mathrm{t}=7500 \mathrm{sec}$

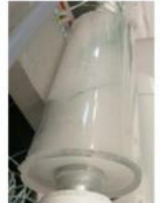

(c) $\mathrm{t}=1000 \mathrm{sec}$

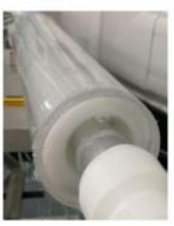

(g) $t=10500$ sec

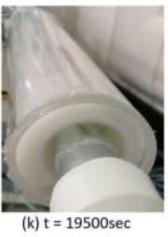

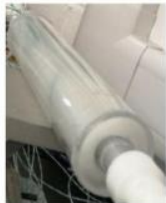

(d) $\mathrm{t}=2000 \mathrm{sec}$

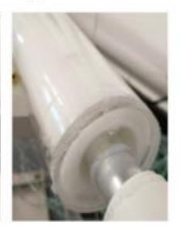

(h) $\mathrm{t}=12500 \mathrm{sec}$

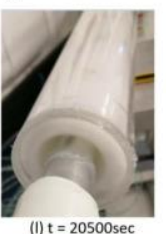

b

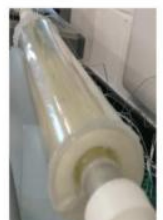

(a) $\mathrm{t}=500 \mathrm{sec}$
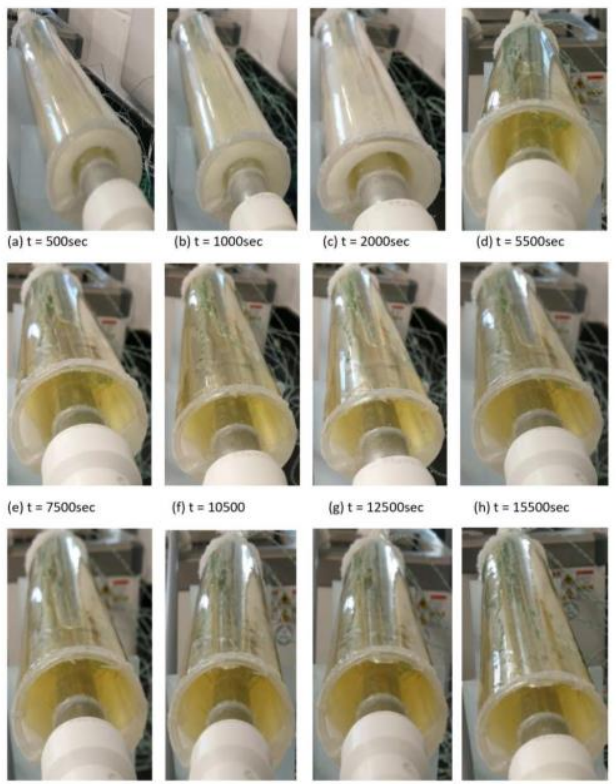

$(\mathrm{g}) \mathrm{t}=12500 \mathrm{sec}$

(h) $\mathrm{t}=15500 \mathrm{sec}$

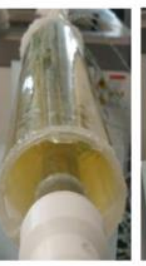

$(k) t=22500 \mathrm{sec}$

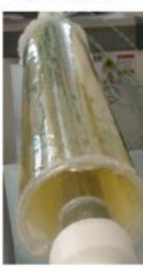

(L) $t=23500$ sec (j) $\mathrm{t}=20500 \mathrm{sec}$

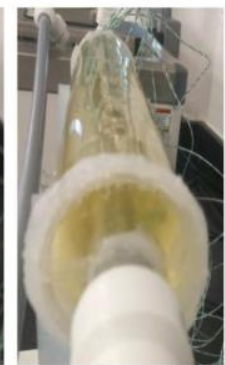

(a) $\mathrm{t}=4000 \mathrm{sec}$

(a) $\mathrm{t}=2000 \mathrm{sec}$
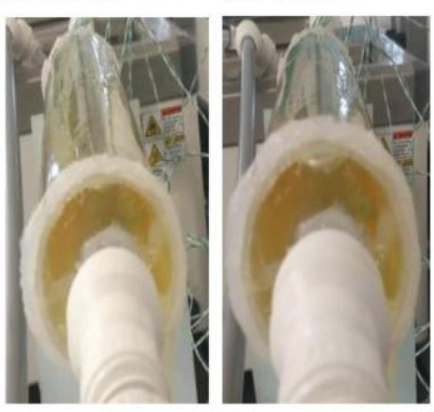

(a) $\mathrm{t}=10500 \mathrm{sec}$

(a) $\mathrm{t}=11500 \mathrm{sec}$

Figure 7 a. Photographs showing the melting progress for horizontal case (heating temperatures $\left.=60^{\circ} \mathrm{C}\right) ; \mathrm{b}$. Photographs showing the melting progress for horizontal case (heating temperatures $=70^{\circ} \mathrm{C}$ ); $\mathrm{c}$. Photographs showing the melting progress for horizontal case (heating temperatures $=80^{\circ} \mathrm{C}$ ). 


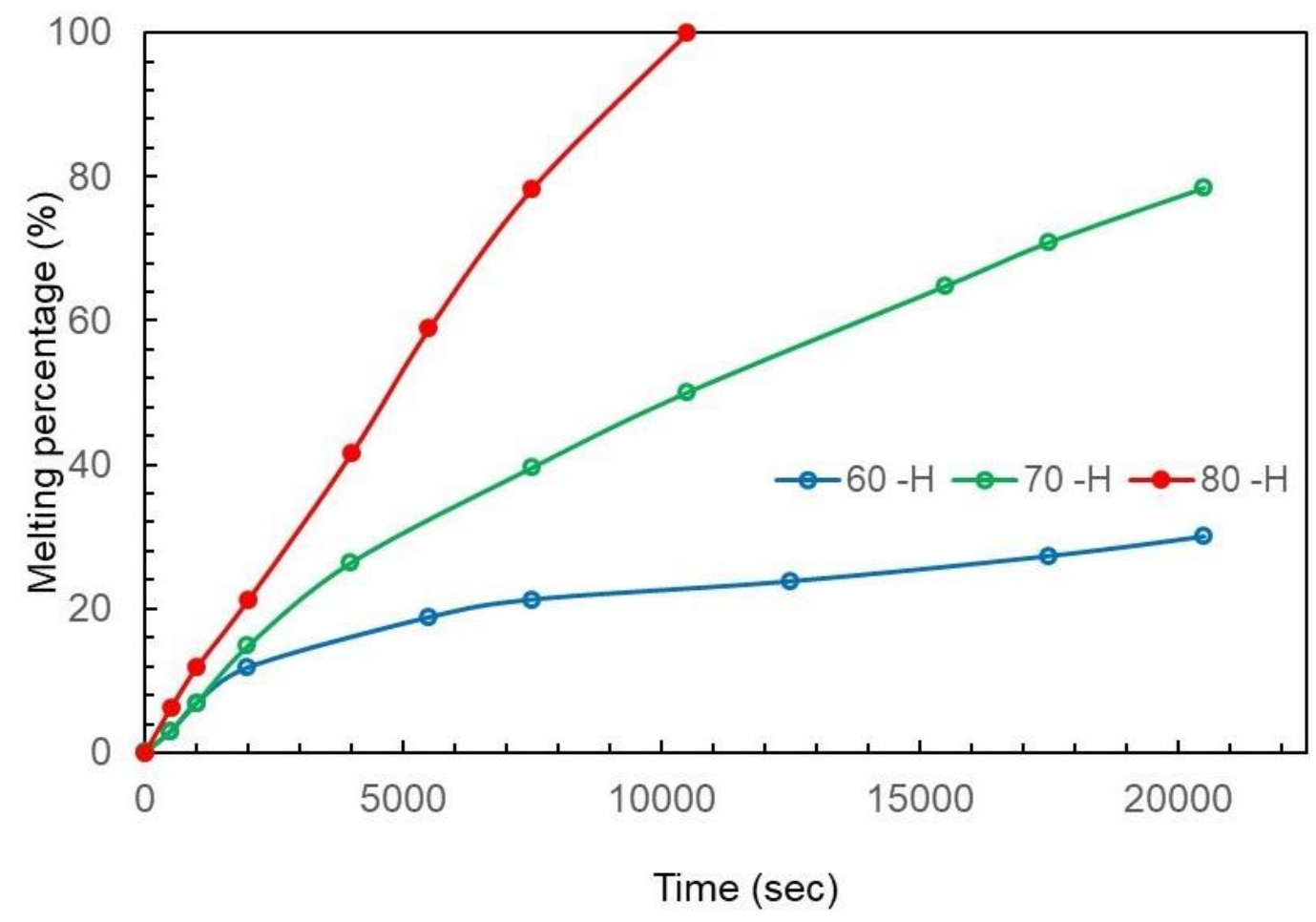

Figure 8 Comparison of melting percentage with time for $60 \circ \mathrm{C}, 70 \circ \mathrm{C}$ and $80 \circ \mathrm{C}$ heating wall ( $\mathrm{H}$ : horizontal case).

Due to the difficulty in calculating the melting percentage before the melting front reach the Perspex pipe wall, the temperature records from thermocouples were used to construct the evolution of melting front using the following procedure:

1. The time for each thermocouple reaching the melting temperature $(338 \mathrm{~K})$ is recoded.

2. The velocity for melting front is calculated from the distance between the first column of the thermocouples and the surface of the aluminium pipe. The same procedure is used for the second and third columns of thermocouples.

3. The velocity and time are used to calculate the distance of the melting front from the aluminium pipe wall.

4. The average diameter of the melting fronts is used to calculate the melted volume. Then the melting percentage calculated by dividing the melted volume by the total annular volume.

As the melting reach the outer surface, the photos from camera are used in combination with calculation of melting front from the temperature records to calculate the melting percentage.

For $333 \mathrm{~K}$ case, Figure 7a shows the photos of the melting progress with the time. From the graph in Figure 8, it can be observed that melted front is moving very fast for the first 2000 secs to reach $22 \%$ as the heat transfer take place by conduction with high temperature difference between the hot surface (inner aluminium cylinder) and the solid PCM. Then, the heat transfer rate reduced with time as the temperature difference between heating surface and melted PCM reduced which led to slower increase in the melting percentage for the rest of time. The melting graph highlighted that melting rate reduced with time due the reduction in heat transfer from the hot wall and the increase in heat losses from the test section as the surface temperature of the outer Perspex cylinder becomes a round $313 \mathrm{~K}$ after 10000 secs, which was higher than the surrounding air ( $295 \mathrm{~K}$ ). The results indicated that the solid PCM layer adjacent to outer Perspex 
wall act as insulating material to reduce the heat losses. The low heat losses increase the temperature of the melted PCM and reduce the heat transfer from the heating wall which delay the PCM melting process.

For $343 \mathrm{~K}$ case, Figure $7 \mathrm{~b}$ shows the photos of the melting progress with the time. From the graph in figure 8 , it can be observed that the melting increased at high rate for the first 4000 secs to reach $40 \%$, then the melting rate reduced with the rest of the time The same explanation given for the case of $333 \mathrm{~K}$ heating temperature are applied to this case. However, melting percentage reached $90 \%$ after 22500 secs compared to $40 \%$ for the $333 \mathrm{~K}$ heating temperature due to the higher temperature of the heating surface. In this case, the higher heating surface temperature increased the overall temperature of the test section, which reduce the influence of solid PCM layer in controlling the heat transfer rate and lead to the high to the melting percentage.

For $353 \mathrm{~K}$ case, Figure $7 \mathrm{c}$ shows the photos of the melting progress with the time.

From the graph in Figure 8 , it can be observed that the melting percentage is increased almost linearly and very fast compared to the cases of $333 \mathrm{~K}$ and $343 \mathrm{~K}$. The melting completed of the PCM was almost completed PCM in 10500 secs. The heat transfer and melting process evolution are very much similar to previous two cases of $333 \mathrm{~K}$ and $343 \mathrm{~K}$.

Figure 9 summarized the melting percentage for the vertical and horizontal cases and the three temperature 333,343 and $353 \mathrm{~K}$. It can be observed that there is melting percentage for horizontal case is twice the melting percentage for $333 \mathrm{~K}$ and reduced to about $20 \%$ for $343 \mathrm{~K}$. However, there is no significant differences for the high temperature of $353 \mathrm{~K}$. The reduction in discrepancy can be attributed to the increases of natural circulation of the melted PCM with highest temperature. It also be observed that the melting percentage reached $100 \%$ after 10500 secs while the melting percentage reached for vertical case reached $91 \%$ at 10000 secs and increased to $95.5 \%$ at 17500 secs. It may take another 10000 s to melt completely. This happen due to the difference in natural circulation mechanism between the two cases.

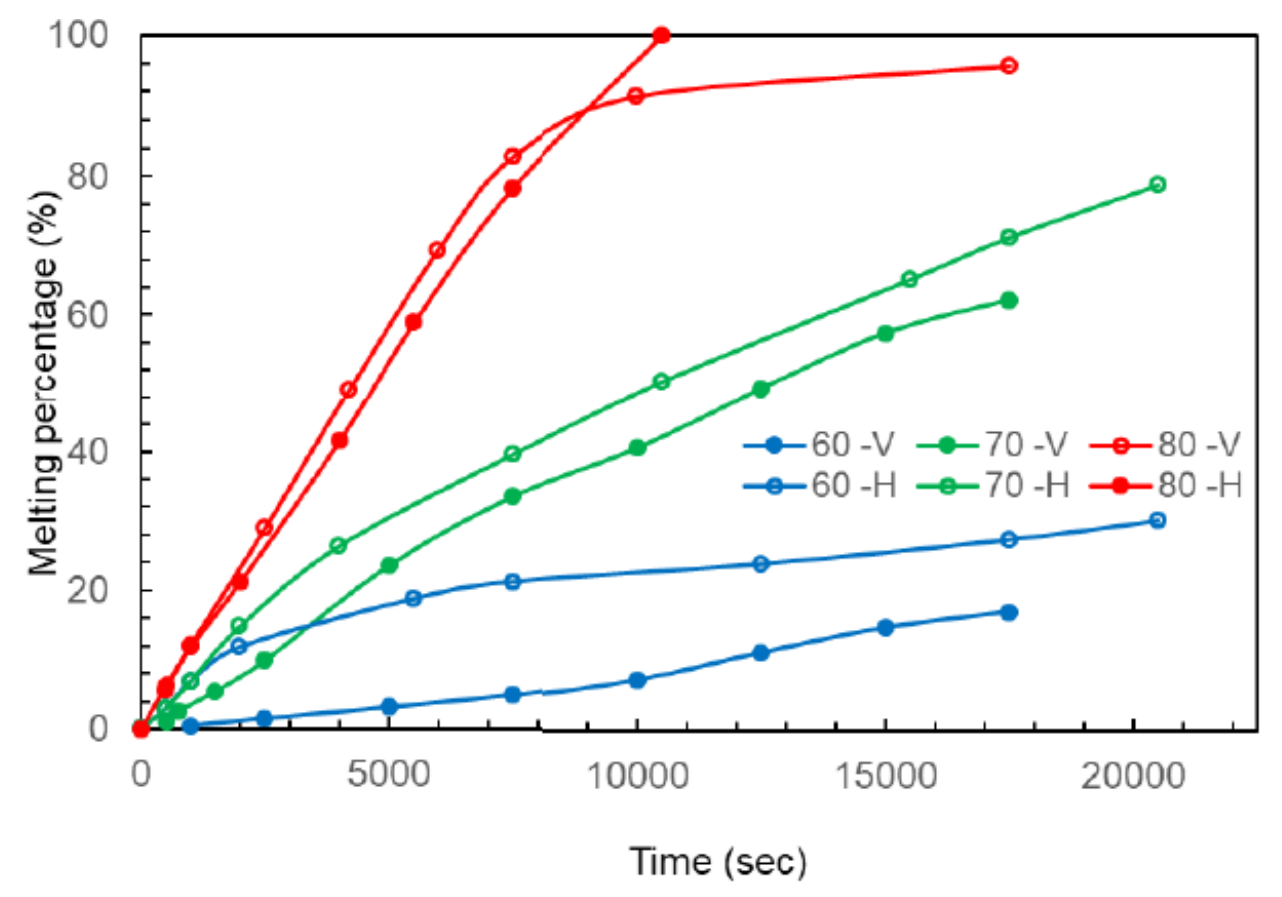

Figure 9 Comparison of melting percentage with time between vertical case ( $\mathrm{V})$ and horizontal case $(\mathrm{H})$. 


\subsection{Solidification Evolution in the Vertical Annular Enclosure}

Solidification is a process controlled by conduction with minor convection as the temperature dropping continuously with time and the melted zone, which lead to continued reduction in natural circulation. While, melting process involves more natural convection than conduction as the temperature maintained higher than melting temperature by the added heat. When the temperature drops to freezing temperature, the natural convection cannot occur, and conduction across the growing solid layer controls the freezing rate. If the liquid is initially superheated, natural convection controls for minor and conduction for long times.

In present work, the temperatures were recorded from the thermocouples inside the PCM after the heating was switched off. The temperature started decreasing gradually with time as shown in Figures 10.

The time for the recoded temperatures in Figure 10 is used to construct the evolution contour of the solidification in similar procedure used for melting profile front. The procedure can be summarized as follows:

1. The time between the turn off time for the heating and the thermocouple reading recording the solidification temperature of $318 \mathrm{~K}$.

2. The velocity of the solidification front is calculated.

3. The location of the solidification front was calculated from the calculated velocity and time.

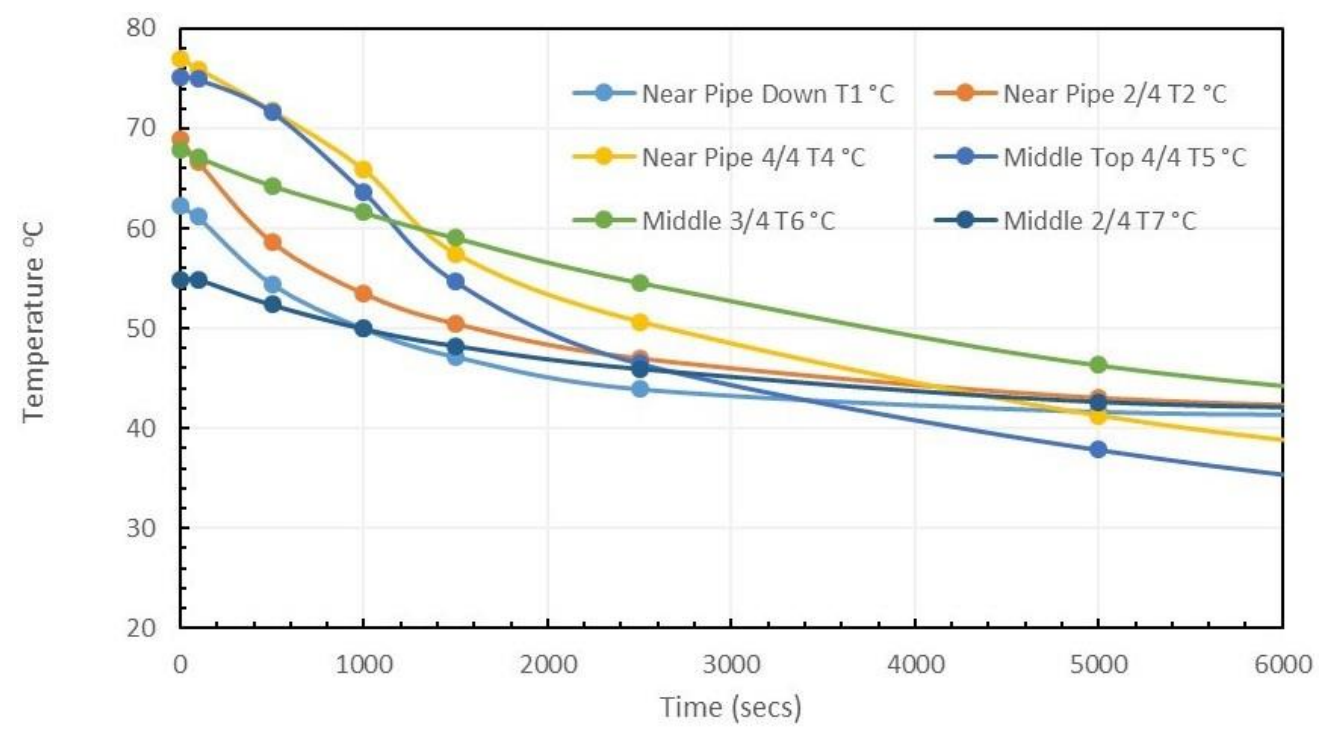

Figure 10 The Variation of temperature with time during solidification $\left(80^{\circ} \mathrm{C}\right)$ (vertical case).

The main difference between melting and solidification is in the movement of the interface. The melting front is moving in radial direction from the inner aluminium wall while the solidification is moving from all outer boundary toward the point of the highest temperature in the inner zone of the PCM. The movement of the solidification is presented in Figure 11. 


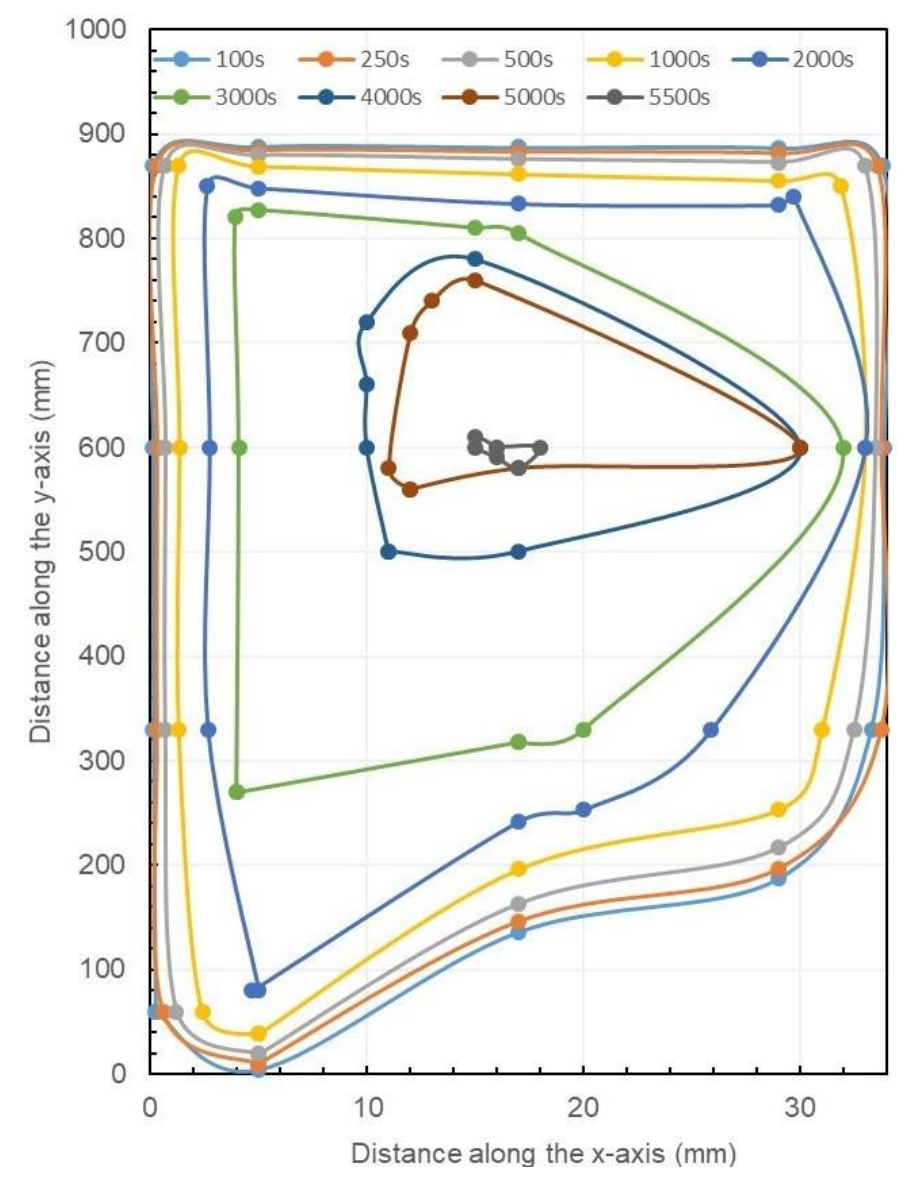

Figure 11 Solidification contour for the hot surface of $800 \mathrm{c}$. (vertical case).

\section{Conclusions}

An experimental investigation has been conducted to investigate the melting behaviour of PCM in a vertical and horizontal annular enclosure between two concentric cylinders for heat storageinsulation applications. The study was performed for vertical and horizontal cases using PEG 1500 for heating surface temperatures of 333,343 and $353 \mathrm{~K}$. It was clearly showed that inclination and heating surface temperature has a significant influence on melting/solidification characteristics. The following conclusions can be drawn:

1. The melting of the PCM in the annular enclosure started initially by conduction and then progressed to convection with the time when melted PCM appear near the heating wall. The results showed that the horizontal annular case melt faster than the vertical case, in particular, at higher heating surface temperature of $353 \mathrm{~K}$.

2. The increase in heating wall temperature showed a large influence on the melting rate of the PCM for vertical and horizontal cases.

3. In the case of solidification, the movement of interface was from the all the outer boundary toward the point of higher temperature at the inner melted PCM. The temperature of the inner region was remained hot for long time which provide a good evidence that support the concept of using the PCM as heat storage -insulation material.

4. The results show that the melting percentage for horizontal case is $100 \%$ higher from the melting percentage of vertical case at $333 \mathrm{~K}$ which reduced to about $20 \%$ for $343 \mathrm{~K}$. However, there is no significant differences for the high temperature of $353 \mathrm{~K}$. The reduction in discrepancy 
can be attributed to the increases of natural circulation of the melted PCM with highest temperature.

\section{Author Contributions}

F. A. Hamad, experimental design, conceptualization, writing, review; E. Egelle, Experimental measurements, literature review and draft preparation for vertical case; Abbas Mohammed, Experimental measurements literature review and draft preparation for horizontal case; $S$. Gooneratne, review and editing; P. Russell, experimental design, conceptualization, writing review; all authors have contributed in reviewing and editing the paper after submission to the journal.

\section{Competing Interests}

The authors have declared that no competing interests exist.

\section{References}

1. Chiu JN, Martin V. Submerged finned heat exchanger latent heat storage design and its experimental verification. Appl Energy. 2012; 93:507-516.

2. Kozak $\mathrm{Y}$, Rozenfeld T, Ziskind G. Close-contact melting in vertical annular enclosures with a non-isothermal base: Theoretical modeling and application to thermal storage. Int J Heat Mass Transf. 2014; 72: 114-127.

3. Yagci OK, Avci M, Aydin O. Melting and solidification of PCM in a tube-in-shell unit: Effect of fin edge lengths' ratio. J Energy Storage. 2019; 24: 100802.

4. Seddegh S, Wang X, Joybari MM, Haghighat F. Investigation of the effect of geometric and operating parameters on thermal behavior of vertical shell-and-tube latent heat energy storage systems. Energy. 2017; 137: 69-82.

5. Ismail KA, Melo CA. Convection-based model for a PCM vertical storage unit. Int J Energy Res. 1998; 22: 1249-1265.

6. Longeon M, Soupart A, Fourmigué JF, Bruch A, Marty P. Experimental and numerical study of annular PCM storage in the presence of natural convection. Appl Energy. 2013; 112: 175-184.

7. Kalapala L, Devanuri JK. Parametric investigation to assess the melt fraction and melting time for a latent heat storage material based vertical shell and tube heat exchanger. Sol Energy. 2019; 193: 360-371.

8. Balikowski JR, Mollendorf JC., Performance of phase change materials in a horizontal annulus of a double-pipe heat exchanger in a water-circulating loop. J Heat Transfer. 2007; 129: 265272.

9. Agyenim F, Eames P, Smyth M. A comparison of heat transfer enhancement in a medium temperature thermal energy storage heat exchanger using fins. Sol Energy. 2009; 83: 15091520.

10. Azad M, Dineshan D, Groulx D, Donaldson A. Melting of Phase Change Materials in a cylindrical enclosure: Parameters influencing natural convection onset. Proceedings of the 4th International Forum on Heat Transfer; 2016 Nov 2-4; Sendai, Japan. Sendai, Japan: Sendai International Center. 
11. Jesumathy SP, Udayakumar $M$, Suresh $S$, Jegadheeswaran $S$. An experimental study on heat transfer characteristics of paraffin wax in horizontal double pipe heat latent heat storage unit. J Taiwan Inst Chem Eng. 2014; 45: 1298-1306.

12. Pahamli Y, Hosseini MJ, Ranjbar AA, Bahrampoury R., Inner pipe downward movement effect on melting of PCM in a double pipe heat exchanger. Appl Math Comput. 2018; 316: 30-42.

13. Tabassum T, Hasan M, Begum L., Thermal energy storage through melting of a commercial phase-change material in a horizontal cylindrical annulus. J Enhanc Heat Transf. 2018; 25: 211 237.

14. Gortych M, Lipnicki Z, Weigand B., An experimental and theoretical study of the solidification process of phase change materials in a horizontal annular enclosure. Appl Therm Eng. 2019; 161: 114140.

15. Mahdi MS, Mahood HB, Hasan AF, Khadom AA, Campbell AN. Numerical study on the effect of the location of the phase change material in a concentric double pipe latent heat thermal energy storage unit. Therm Sci Eng Prog. 2019; 11: 40-49.

16. Seddegh S, Wang $X$, Joybari MM, Haghighat F. Investigation of the effect of geometric and operating parameters on thermal behavior of vertical shell-and-tube latent heat energy storage systems. Energy. 2017; 137: 69-82.

17. Al Siyabi I, Khanna S, Mallick T, Sundaram S. An experimental and numerical study on the effect of inclination angle of phase change materials thermal energy storage system. J Energy Storage. 2019; 23: 57-68.

18. Hamad FA, Egelle E, Cummings K, Russell P. Investigation of the melting process of polyethylene glycol 1500 (PEG 1500) in a rectagular enclosure. Int J Heat Mass Transf. 2017; 114: 1234-1247.

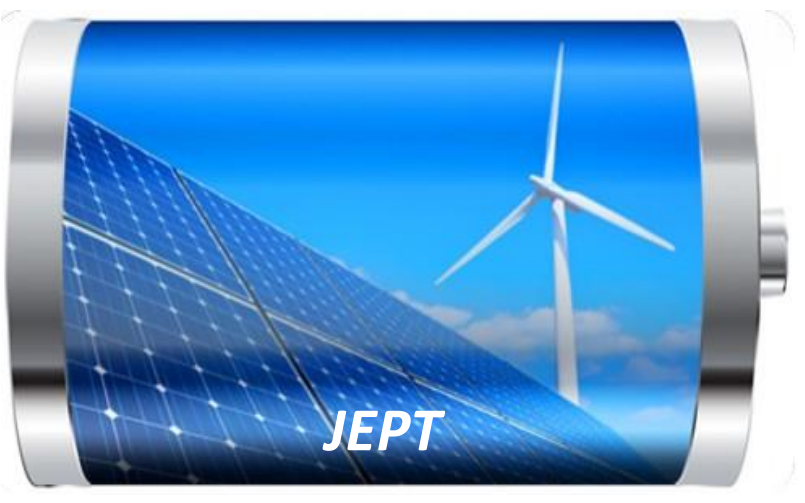

Enjoy JEPT by:

1. Submitting a manuscript

2. Joining in volunteer reviewer bank

3. Joining Editorial Board

4. Guest editing a special issue

For more details, please visit:

http://www.lidsen.com/journal/jept 